\title{
The Hebei Agricultural Production Vulnerability Assessment
}

\author{
Rufei Zhang \\ Institute of economic and trade \\ Shijiazhuang University of Economics \\ Shijiazhuang, China \\ E-mail: zhangrufei1982@163.com
}

\author{
Lijun Liu \\ Institute of economic and trade \\ Shijiazhuang University of Economics \\ Shijiazhuang, China \\ E-mail: blue800410@126.com
}

\begin{abstract}
In this paper, the agricultural production of Hebei Province as the research object, By analyzing the relationship between agricultural production and natural disaster losses strength, Set up a elastic coefficient model of production vulnerable and use production and vulnerable elastic analysis method. Above all, we evaluate the agricultural production in Hebei Province on the capacity of the natural disasters, which proves frequent occurrence of agricultural natural disasters in recent 10 years of Hebei Province. But agricultural production continued to grow in the cause.
\end{abstract}

Keywords-Natural disaster; Vulnerability elastic coefficient model; Agricultural production

\section{INTRODUCTION}

Hebei province is a traditional agricultural province, which is located in the north China plain. The total agricultural output value holds the considerably large proportion in the national economy total output value. However, since for many years due to general rural economies and engineering factors are backward, agricultural production is severely affected by natural disasters. From the year 1995 to 2011, the Hebei average the stricken area amounts to 2382.80 thousand hectares every year, the disaster area amounts to 1448.64 thousand hectares, the disaster area accounts for the stricken area $56.13 \%$. 1995-2011 years of Hebei in the past years disaster area, stricken area as well as total agricultural output value as shown in Fig. 1. And, 1995-2003 Hebei province have affected an area of over 2 million hectares, 1999, 2000, 2002 years of disaster area is reaches as high as over 3.5 million hectares. During this period, the Hebei gross farm production growth is slow, 1999 and in 2000 even had the negative growth, the natural disaster has had the serious influence to the agricultural production. 2004-2011 years of Hebei stricken area below 2 million hectares, the total agricultural output value promotes rapidly, the average changes achieve $14.36 \%$, in 2010 the total agricultural output value rate of increment is astonishing reaches as high as $26.10 \%$. Hebei has the natural disaster every year; Does the total agricultural output value have what kind of quota relation with the natural disaster?

In the past regarding the research of total agricultural output value, enhances the per unit area yield level two aspects to start from the expanded sown area. Former increases scale of agricultural production, latter raises efficiency of agricultural production, but both are subject to the impact of natural disasters. Regarding the genetic mechanism and spatial- temporal distribution natural disaster, our country scholars have done the massive research work. However in social economy vulnerability the research regarding the natural disaster still waits for further thorough, In particular, how to evaluate the disaster vulnerability of agriculture economy in China, The relevant research are few at present, Therefore, This article attempts to construct a scientific evaluation standard to reflect the disaster vulnerability of agricultural production.

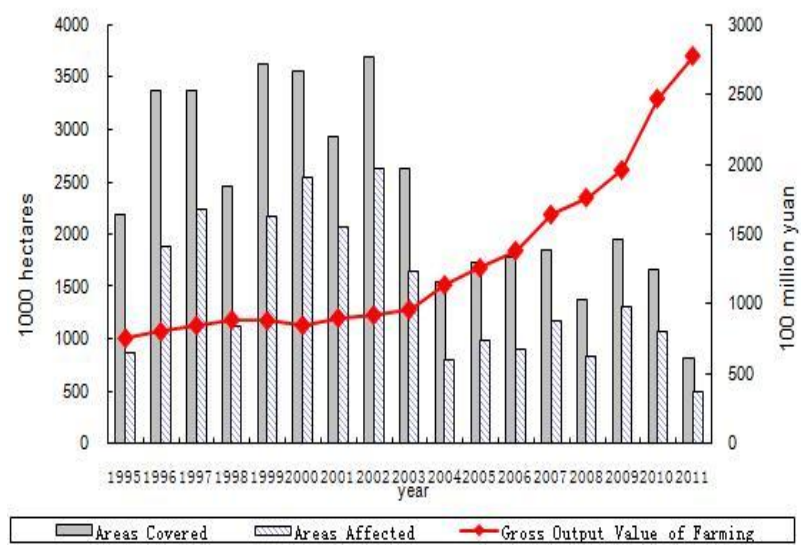

Figure 1. 1995-2011 Hebei disaster area, stricken area and total agricultural output value

\section{AGRICULTURAL PRODUCTION VULNERABILITY ISSUE}

Vulnerability refers to the things nature of susceptible to damage, it reflects the capacity of things under certain conditions to natural disasters, the research of economical vulnerability assessment issue started 60 to the 70's in the 20th century. Costs mainly_ the expenditure of benefit analysis law determination disaster prevention mechanical control measure. However, evaluation of natural disasters on economic activities in the production process, and total economic (Output value, output)impact, there should be more precise, to reflect the dynamic changes of total disaster and economic indicators.

Vulnerability of agricultural production is to refer to the bearing capacity of agricultural production to natural disaster. From process of agricultural production, there are four main indicators can reflect the situation of agricultural production and natural disaster, first, total agricultural output value $G$, Second, agricultural sown area S, Third, agricultural unit output value $\mathrm{P}$, Fourth, disaster area in the agricultural production process $\delta$. If looks at these four targets isolated, 
they are the static states, cannot conclude that its relationship with the vulnerability of agricultural production, it must discover its intrinsic relation, to accurately reflect the capacity of agricultural production on natural disasters. To this end, the authors try to introduce the elastic analysis methods in economics to research on vulnerability assessment of agricultural production.

Flexibility was originally a concept in physics, which refers to the response intensity of object to external force. In the economic, this word refers to having among the economic variables of functional relations, an extent of reaction of variable to another variable change. The elastic modulus is a quantity of non-dimensional. In the four variables, the total agricultural output value is the sown area and function of agricultural unit output value, That is, $G=F_{1}(S, P), F_{1}$ is increasing function, in the agricultural production natural disaster loss intensity is the sown area and disaster area function, occupies the sown area the ratio to indicate with the disaster area, $D=\delta / S$, The natural disaster loss intensity of the total agricultural output value and agricultural production has the functional relations, $G=F_{2}(D), F_{2}$ is reduced function.

With method of elastic analysis, defining to the response of natural disaster loss variation of intensity the total agricultural output value as the total output value vulnerable elastic modulus Egd, Then there are

$$
E g d=\frac{\Delta G / G}{\Delta D / D}=\frac{\Delta G \cdot D}{G \cdot \Delta D}
$$

From type (1), Total output value vulnerable elastic modulus is the reflection natural disaster loss variation of intensity and non-dimensional quantity of total agricultural output value change relations.

\section{PROPERTIES OF EGD}

Now to discuss the nature and significance of Egd, from (1) it can be concluded that $E g d=\frac{\Delta G}{\Delta D} \cdot \frac{D}{G}$

If $\Delta D \rightarrow 0$,

$$
E g d=\lim _{\Delta D \rightarrow 0}\left(\frac{\Delta G}{\Delta D} \cdot \frac{D}{G}\right)=\frac{d G}{d D} \cdot \frac{D}{G}
$$

By type (2) can be seen, $d G / d D$ Is total agricultural output value - marginal propensity of natural disaster loss variation of intensity, $G / D$ is gross output value of agriculture--natural disaster loss strength average tendency, therefore, Output elastic coefficient and vulnerability Egd is the meaning of using marginal propensity divided by average tendency. When G is D one circular function, it can extract the marginal propensity with the derivative, When $G$ is $D$ functions of many variables, and available partial derivative sought the marginal propensity. Finding the derivative of is risen - loss of natural disasters on the intensity function of a point change in rates, in other words Egd is point elasticity. In same total agricultural output value - in natural disaster loss intensity curve, different natural disaster loss intensity correspondence has the different total agricultural output value. Using this method, Ccn under the condition of known Egd stricken degree, forecast the total agricultural output value, perhaps surveys the natural disaster loss intensity in known Egd and situation of total agricultural output value.

Different working condition and change of disaster reduction ability, which has different total agricultural output value - natural disaster loss intensity curve, total output value vulnerable elastic modulus Egd is different. Because the total agricultural output value $\mathrm{G}$ is the natural disaster loss intensity $\mathrm{D}$ decreasing functions, $d G / d D<0$, Value of Egd is a negative number, As shown in figure 2 shows.

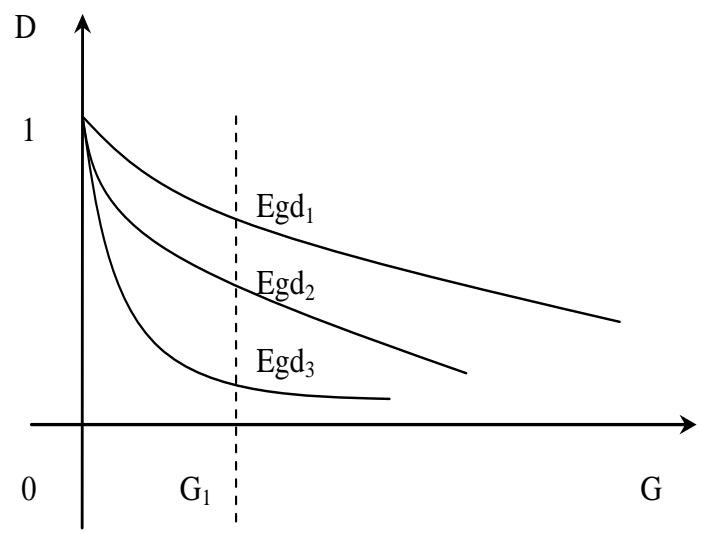

Figure 2. Total agricultural output value - natural disaster loss intensity

It can see from Fig 2, When a natural disaster loss of strength $D=1, S=\delta$, Namely complete sown area causes disaster, total agricultural output value $G=0$, Different working condition has different total agricultural output value natural disaster loss intensity curve, although can deliver the same total agricultural output value $G_{1}$, However total output value vulnerable elastic modulus under the dissimilar condition Egd is different, In Figure 2 is not equivalent to Egd,

Egd, $\operatorname{Egd}_{3}$.

\section{ANALYSIS OF THE VULNERABILITY OF AGRICULTURAL PRODUCTION IN HEBEI PROVINCE}

Following using elastic analysis France, Egd analyzes the Hebei agricultural production at the total output value vulnerable elastic modulus the natural disaster vulnerability issue. Select 1995-2011 analysis on natural disasters in agricultural production of Hebei province as object. 
TABLE I. 1995-2011 YEARS OF HEBEI AGRICULTURAL PRODUCTION

\begin{tabular}{ccccccc}
\hline Year & $G(1000$ million yuan $)$ & $\Delta G$ & $S(1000$ hectares $)$ & $\delta$ (1000 hectares $)$ & $D$ & $\Delta D$ \\
\hline 1995 & 753.52 & - & 8720.10 & 857.00 & 0.0983 & - \\
1996 & 801.26 & 47.74 & 8872.10 & 1880.90 & 0.2120 & 0.1137 \\
1997 & 845.18 & 43.92 & 8856.90 & 2231.30 & 0.2519 & 0.0399 \\
1998 & 885.88 & 40.7 & 9097.70 & 1120.00 & 0.1231 & -0.1288 \\
1999 & 879.64 & -6.24 & 9055.20 & 2170.00 & 0.2396 & 0.1165 \\
2000 & 846.72 & -32.92 & 9024.40 & 2541.30 & 0.2816 & 0.0420 \\
2001 & 899.38 & 52.66 & 8990.80 & 2063.34 & 0.2295 & -0.0521 \\
2002 & 918.62 & 19.24 & 8935.10 & 2617.45 & 0.2929 & 0.0634 \\
2003 & 958.30 & 39.68 & 8638.50 & 1644.44 & 0.1904 & -0.1026 \\
2004 & 1135.75 & 177.45 & 8695.40 & 797.52 & 0.0917 & -0.0986 \\
2005 & 1258.00 & 122.25 & 8785.50 & 976.02 & 0.1111 & 0.0194 \\
2006 & 1380.45 & 122.45 & 8713.90 & 899.86 & 0.1033 & -0.0078 \\
2007 & 1639.07 & 258.62 & 8652.70 & 1170.21 & 0.1352 & 0.0320 \\
2008 & 1760.75 & 121.68 & 8713.20 & 818.29 & 0.0939 & -0.0413 \\
2009 & 1958.79 & 198.04 & 8682.50 & 1301.12 & 0.1499 & 0.0559 \\
2010 & 2470.11 & 511.32 & 8718.40 & 1058.29 & 0.1214 & -0.0285 \\
\hline
\end{tabular}

Note: The data originates from Hebei Economical Yearbook

According to table 1, we can calculate from Hebei province in 1996-2011 risen wearing elastic coefficients $E g d$, Concrete value as shown in Table 2.

TABLE II. 1996 TO 2011 HEBEI TOTAL AGRICULTURAL OUTPUT VALUE VULNERABLE ELASTIC MODULUS EGD

\begin{tabular}{cc||cc}
\hline Year & Egd & Year & Egd \\
\hline 1996 & -0.1111 & 2004 & -0.1453 \\
1997 & $0.3279 *$ & 2005 & -0.5572 \\
1998 & -0.0439 & 2006 & -1.1703 \\
1999 & -0.0146 & 2007 & -0.6674 \\
2000 & -0.2609 & 2008 & -0.1570 \\
2001 & -0.2579 & 2009 & -0.2708 \\
2002 & -0.0967 & 2010 & -0.8826 \\
2003 & -0.0768 & 2011 & -0.0902 \\
\hline
\end{tabular}

Note: the above marked with $*$ is an exception value

It can see from Table 2 that was bigger than zero except 1997 total output value vulnerable elastic modulus Egd the positive number value, did not conform to the Egd nature, can think that was the outlier, other points very good with total agricultural output value - natural disaster loss intensity curve nature tallied, namely conformed to the Egd nature.

$\overline{|E g d|}$ Of 1996-2004 is (After removing outliers of 1997)

$$
\overline{|E g d|}=\frac{\sum|E g d|}{N}=0.1259 \quad N=8
$$

This indicates for 1996-2004 years, in the Hebei agricultural production natural disaster loss intensity D increases $1 \%$ every time, the agricultural unit output value must reduce $12.59 \%$

Similarly available, $\overline{|E g d|}$ of 2004-2011 is

$$
\overline{|E g d|}=\frac{\sum|E g d|}{N}=0.4926 \quad N=8
$$

This indicates for 2004-2011 years, in the Hebei agricultural production natural disaster loss intensity D increases $1 \%$ every time, the agricultural unit output value must reduce $49.26 \%$, Otherwise, natural disaster loss intensity D every time reduces $1 \%$, the agricultural unit output value can grow $49.26 \%$.

The analysis above shows that, Hebei total agricultural output value in 1996-2004 years of Egd compared with 20042011 years of Egd low 36.67 percentage points. In other words, when 1996-2004 years of each additional unit natural disaster loss intensity compared with 2004-2011 years of each additional unit natural disaster loss intensity, the agricultural unit output value loses $36.67 \%$ slightly. Thus, while 1996-2004 agricultural disaster loss frequency and intensity is higher than 2004-2011, but it's lower than 2004-2011 per unit of production value loss.

\section{CONCLUSION}

Input factor of production in agricultural production has more than one, which is more or less an impact on disaster mitigation and resilience. The elastic analysis law can well reflect the dynamic characteristics of agricultural production to stricken degree change as a whole, total agricultural output value vulnerable elastic modulus Egd can the sensitivity of comprehensive reflection agricultural production process to natural disaster. Using total agricultural output value vulnerable elastic modulus analysis, can appraises to the different local and different types of agricultural production vulnerability, scientifically agricultural production resisting natural calamities production capability of quite different local agricultural production process bearing capacity or to natural disaster.

\section{REFERENCES}

[1] Jiang Tong,XuPengzhu, Natural disasters in the study of social vulnerability assessment $[\mathrm{J}]$, Journal of Chinese Academy of Sciences, 1996 
[2] Kong Yuanyuan, Xu Gang, Chongqing natural disaster to agricultural economy development influence and countermeasure [J]. Agricultural economy, 2008

[3] Zhang Yi. The stable agriculture is to guarantee economical smooth development l"consistencyl" [N]. The people's daily, 2009.

[4] Lu Yao. Evolution of social functions of agriculture in China and their interpretation [j]. Resources science, 2011. 